\title{
EFFECT OF FRICTION ON THE MICROMECHANICAL PROPERTIES OF AISI 316L AUSTENITIC STEEL
}

\author{
Daria Grabco ${ }^{1 *}$, ORCID: 0000-0002-4319-367X, \\ Constantin Pyrtsac ${ }^{1,2}$, ORCID: 0000-0002-7775-237X, \\ Daria Topal ${ }^{1}$, ORCID: 0000-0003-1960-4747, \\ Olga Shikimaka ${ }^{1}$, ORCID: 0000-0003-4055-3761 \\ ${ }^{1}$ Institute of Applied Physics, Chisinau, Moldova Rep. \\ ${ }^{2}$ Technical University of Moldova, Chisinau, Moldova Rep. \\ *Corresponding author: Daria Grabco,grabco@mail.ru
}

Received: 17.04.2021

Accepted: 10.05 .2021

\begin{abstract}
In this paper, we investigate the possibility of using the friction method for modifying the microstructure and mechanical properties in the near-surface regions of AISI 316L austenitic steel specimens for the purpose of its practical application. It is shown that a region of severe plastic deformation arises near the friction surface, which transforms the initial fine-grained polycrystalline steel structure into a homogenized zone consisting of a deformed structure with plastic slip bands and weakly pronounced grain boundaries. The change in the microscopic structure results in an increase in this zone of values of micromechanical characteristics, such as microhardness $(H)$, Young's modulus $(E)$, plasticity index $(H / E)$ and resistance index $\left(H^{3} / E^{2}\right)$. The obtained results are of interest for the potential use of AISI 316L steel in medicine.
\end{abstract}

Keywords: AISI 316L steel, friction, microstructure, strength and plasticity parameters.

\section{Introduction}

It is well known that the resistance that occurs when two surfaces are in contact with each other and are subjected to a force that makes them slide relative to each other is so called frictional force. From a physical point of view, friction is a complex and diverse phenomenon. Over the years, various hypotheses and models of friction have been advanced and substantiated. So, three consecutive and interrelated stages of the friction process were formulated, namely [1 - 3]:

- interaction of contacting surfaces, taking into account the influence of the environment;

- changes in the microstructure of surface layers as a result of interaction;

- destruction of surfaces due to the two previous stages.

The determining factor in this is the first stage, the interaction of surfaces, since the course of subsequent stages, the modification of the microstructure and the change in mechanical properties depend on its intensity.

In this regard, a large number of works are devoted to the influence of friction on the transformation of the internal structure and mechanical parameters [4 - 7]. Thus, in [4], the 
relationship between bulk hardness (Rockwell macrohardness), surface hardness (Vickers microhardness) and strain hardening rate with the frictional behavior of $\mathrm{Cu}-\mathrm{Sn}$ and $\mathrm{Cu}-\mathrm{Al}$ alloys is considered. The highest microhardness was recorded immediately below the wear surface, and its value increases with an increase of the instantaneous rate of strain hardening. However, there was no correlation found between the strain hardening rate and bulk hardness. In [5], the friction stir processing (FSP) was undertaken to harden the surface of high carbon martensitic stainless steel (AISI 440C) and increase its corrosion resistance. Friction stirring processing has also been used to improve the grain structure of AISI 316L stainless steel. Microstructural studies using transmission electron microscopy have shown that the grain structure evolution in the mixing zone is mainly determined by intermittent dynamic recrystallization. Compared to the base metal, the FSP specimens showed higher hardness, increased yield and tensile strength. The authors attributed the improved values of mechanical parameters to the improvement of the grain structure [6].

Analysis of the avaible experimenrtal data indicates a close relationship between the mechanical characteristics of various metallic materials and their microstructure, which makes it possible to purposefully perform changes in their mechanical properties. Currently, various methods are already used in technology to improve hardness, yield and tensile strength, wear resistance, etc. For example, ion implantation causes changes in the surface composition or morphology of solids, as a result of which the values of hardness and elastic modulus increase [8]. The additive manufacturing (AM) methods widely used in industry, such as laser powder surfacing [9], steel processing by melting, the use of high-temperature preheating systems [10], have great possibilities in modifying mechanical properties.

Considering that for technical goals the new materials with various and specific properties are required, the search continues for new ways to change the microstructure and strength characteristics of them, depending on their practical purpose. In [11 - 14] it was demonstrated that after friction the microstructure of a narrow surface layer of metal samples (brass, copper, steel) differs significantly from the microstructure in the bulk of them. The reason for this difference is that near the surface of friction, the material is subjected to ultra-high internal stresses that are much stronger than in the bulk. Under such conditions, a significant change in the behavior of the material and, naturally, the appearance of anomalous phenomena of mass transfer occur [2, 3, 15, 16]. This problem is currently still insufficiently studied and it is necessary to carry out special studies on this subject.

Therefore, the main task of this paper is to consider the effect of friction on the micromechanical parameters of austenitic stainless steel AISI 316L. We mention that, the use of this material is extremely widespread in various areas of the economy, including medicine, in particular, in surgery and dentistry as implants. Moreover, implants used in bone surgery and dentistry should have, similarly to bone tissue, increased hardness in a narrow surface layer of the material compared to hardness in the bulk. Thus, taking into account the previos results from the literature, the creation of such mechanical properties can be achieved by applying the friction method.

\section{Experimental}

The investigated samples of AISI 316L stainless steel were the washers $(15 \times 15 \times 5)$ $\mathrm{mm}$ in size with the following chemical composition, \%: ( C 0.019; Mn 1.74; P 0.017; S 0.001; Si 0.5;Cr 17.38; Ni 14.24; Mo 2.85; N 0.062; Cu 0.1; Fe 63.09). Studies of the 
deformation specificity of AISI 316L steel were carried out for two friction modes: 1 - dry friction "metal/metal", namely, steel AISI 316L/steel St3sm, and 2 - dry friction "metal/abrasive", namely, steel AISI 316L/abrasive P2000, with different duration of the process ( $t=1 ; 5$ and 10 hours). Friction processes were carried out on a friction device, a MoPao 160E polishing machine and manually. The study of the modification of the microstructure as a result of friction and the determination of the mechanical parameters were carried out on the cross sections of the samples.

The study of hardness was carried out by two methods: the method of instrumental (depth-sensitive) indentation on a Nanotester-PMT3-NI-02 device equipped with a Berkovich indentor, at a load of $P=400 \mathrm{mN}$, and by the method of quasi-static indentation using an PMT-3 microhardness tester, load on the indenter was $500 \mathrm{mN}$. The depthsensitive indentation method has a higher measurement accuracy compared to the quasistatic indentation method [17,18]. Quasi-static indentation studies the 'post-factum' process, after removal of the load, while instrumental indentation studies the process of indentor penetration and removal of the load in dynamics, thereby allowing, along with the assessment of hardness $(H)$ and Young's modulus $(E)$, to determine many other mechanical characteristics. The testing on nanotester were performed as follows. Loading process - 20 $\mathrm{s}$, holding at maximum load $\left(P_{\max }\right)-30 \mathrm{~s}$, unloading - $20 \mathrm{~s}$. For each load, 10 imprints were applied. The results were calculated as the average of 10 tests. Based on the analysis of the indentation curves, the main parameters of elasticity, plasticity, and strength were estimated. The calculations were carried out according to the Oliver-Pharr method widely used in science [19]. All calculations were performed automatically using the instrument software.

Finally, the microstructure of the surface of samples and the relief of the zone in the vicinity of the hardness imprints were investigated by optical microscopy using Amplival and XJL-101 instruments with digital monitoring. Selective chemical treatment in order to identify the grain structure was carried out in a solution of the composition: $2.5 \mathrm{ml} \mathrm{HCl}+1$ $\mathrm{ml}$ glycerol $+0.5 \mathrm{ml} \mathrm{HNO3}$, etching time $t_{\mathrm{ct}} \approx 5 \mathrm{~min}$.

\section{Results and Discussion}

The initial micrograin structure of the AISI 316L stainless austenitic steel, revealed by the method of selective chemical etching, is shown in Figure 1. The grain size of the sample ranges from 2 to 50 $\mu \mathrm{m}$.

One can clearly see that crystallites have different shapes and orientations not only on the surface under study, but also relative to their location in the volume, which is confirmed by the different microstructure and color of the crystallites. Figure 2 shows the shape of imprints made on the cross section of sample at different distances from the friction surface.

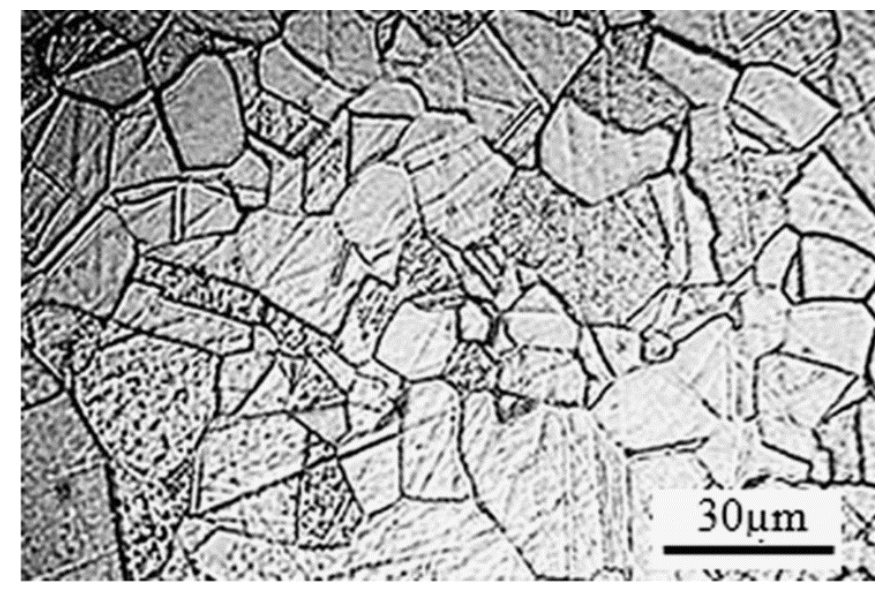

Figure 1. Microstructure image of surface of AISI 316L austenitic stainless steel after chemical etching. 

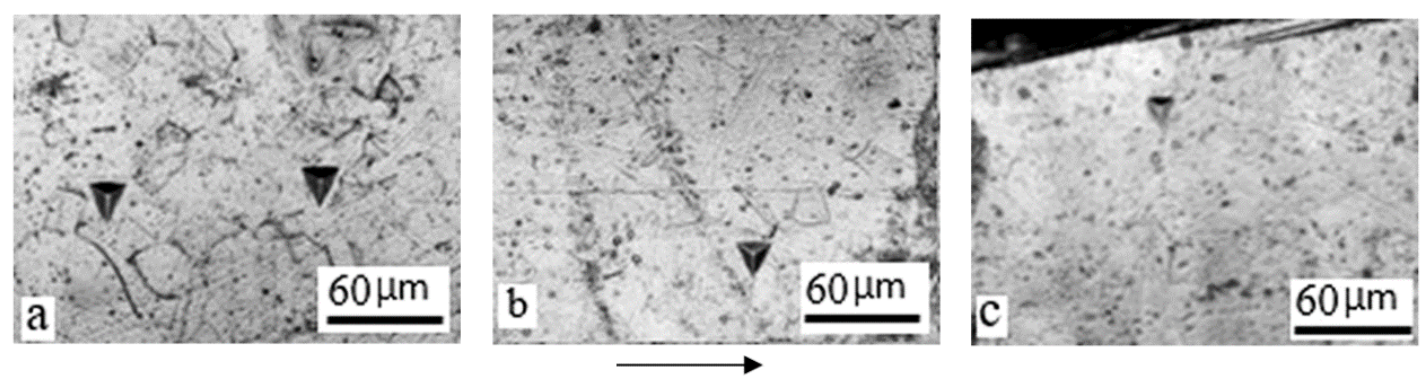

Figure 2. Images of sample microstructure and of imprints, made at different distances from the friction surface. Conditions: dry friction "metal/metal", AISI 316L steel/ St3sm steel; friction duration $t_{\mathrm{fr}}=1$ hour, the arrow indicates the direction to the surface.


Figure 3. AISI 316L austenitic steel. Evolution of changes in the microstructure of a sample at a cross section as it approaches the surface that has been subjected to friction for 1 hour (sliding lines are marked with arrows). 
It is also seen that far from the friction surface (Figure 2 a) the sample has a fine-grained structure. As they approach the friction surface shown in Figure 2 b, c, the crystalline granules are smoothed out and are very faintly visible near the friction surface. At the same time, attention is drawn to the fact that the size of the imprints decreases as they approach the surface. This indicates a change in the value of hardness, the smaller the imprint, the higher the hardness. This issue will be considered in more detail below.

Analysis of the surface shape at higher magnification reveals new details of the evolution of the microstructure that occurs in the sample under the influence of friction (Figure 3). Here the pictures are presented in order of approach to the friction surface (Figure 3 a-f). It can be seen that deformation slip bands intersect inside the grains (shown by arrows). Sliding bands cross different grains
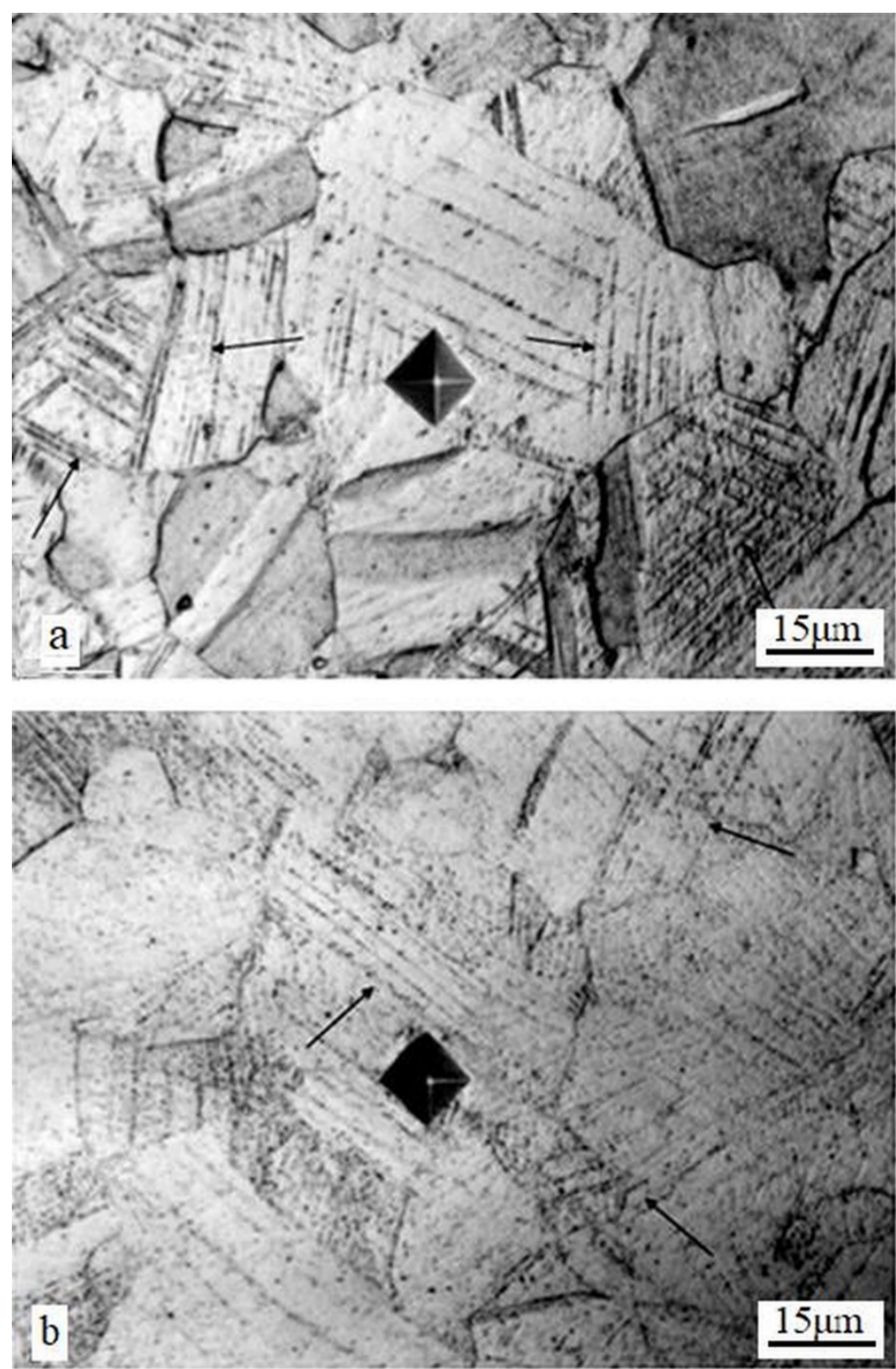

Figure 4. AISI 316L austenitic steel. Pictures from Figure $3 \mathrm{~b}$ and $3 \mathrm{f}$ at an increased magnification. resulting in a smoothing of the grain boundaries shown in Figure $3 \mathrm{~d}$-f. In this case, the color of grains is leveled, i.e. their disorientation decreases. When crystallites have different crystallographic orientations with respect to the studied surface, they have different degrees of color (see Figure 3 a-b).

As the degree of deformation of the material increases when approaching the friction surface, the color of the grains evens out, and in the last pictures of Figure $3 \mathrm{e}, \mathrm{f}$ the surface becomes more uniform and evenly colored, the grain boundaries are less pronounced, and the grains themselves acquire a similar orientation. So, we can say that the closer to the friction surface, the more the sample structure is homogenized and already consists of a uniformly deformed structure with plastic slip bands and weakly pronounced grain boundaries; compare the results of Figure $3 b$ and $3 f$ at higher magnification shown in Figure 4.

The same pattern is observed for other modes and methods of friction. For instance, a sample subjected to "metal/metal" friction is shown in Figure 5.

The presented stages are similar to Figure 3, and demonstrate the evolution of the microstructure as a result of 10 -hour friction of the AISI $316 \mathrm{~L}$ steel/St3sm steel pair of 
samples. A similar modification of the internal structure of the material under the action of prolonged dry friction is seen, as for one-hour friction: the appearance of deformation slip bands inside the grains, intersection with other grains, and the homogenization of the crystallographic orientation of the grains.


Figure 5. AISI 316L austenitic steel, a-d - the evolution of microstructure changes of the sample at a cross section as the friction surface approach. Friction duration - 10 hours.

Similar changes can be traced on a sample subjected to 5 -hour manual friction using the "metal/abrasive" method, AISI 316L steel/P2000 abrasive (Figure 6).

The multi-grain structure of the surface is clearly visible at a large distance from the friction surface $(\approx 700 \mu \mathrm{m}$ ) shown in Figure 6 , a and its transformation into a smooth homogeneous structure at a distance of $\approx 50 \mu \mathrm{m}$ from the friction surface as in Figure $6 \mathrm{c}$.

The noted appearance of a more homogeneous structure near the friction surface with a smaller misorientation of grains correlates with the results of studies in which, for different friction regimes, the formation of a fragmented structure with a smaller angle of grain misorientation was also recorded than in the original undeformed samples. For example, in [6] it is shown that as a result of friction with stirring of AISI 316L stainless steel, the number of high-angle boundaries has decreased, instead of this, the number of low-angle boundaries has significantly increased.

The homogenization of the sample structure near the friction zone was also confirmed by the results of works in which the study of the internal structure of the samples after various methods of friction was carried out by the methods of transmission and scanning electron microscopy, atomic force microscopy and the electron diffraction method $[2,3,20]$. 

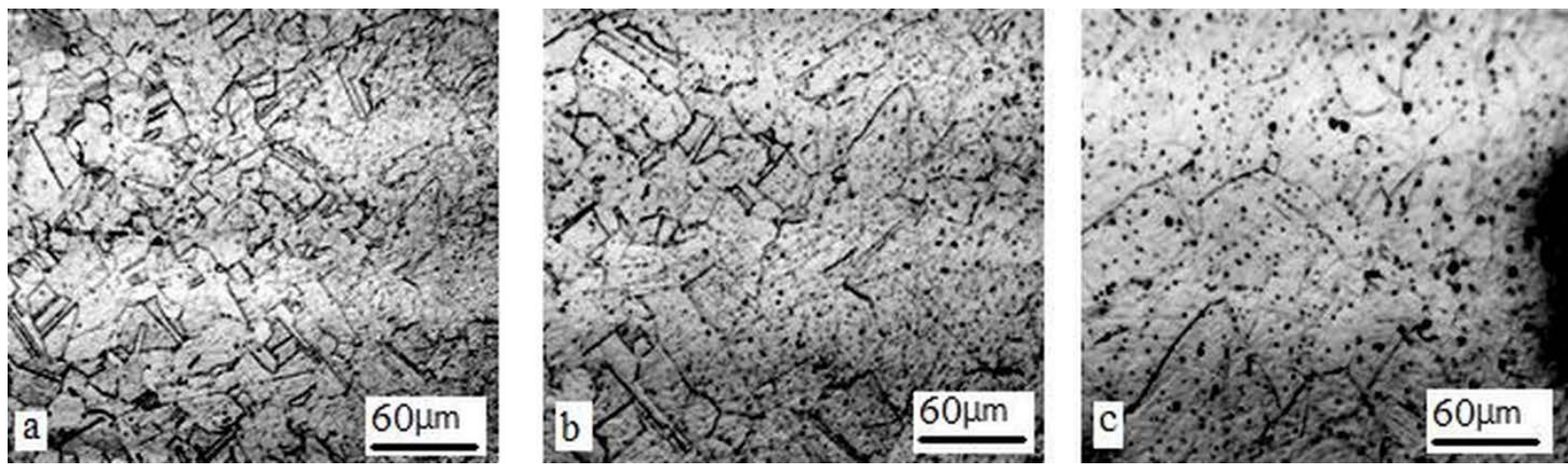

Figure 6. AISI 316L austenitic steel. Evolution of the modification of sample microstructure at a cross section as the surface approach $(a-b-c)$ subjected to manual polishing for 5

hours.

Changes in the microscopic structure of samples subjected to different methods of friction and different duration of the friction process, as a result, led to a change in micromechanical characteristics, such as microhardness $(H)$, Young's modulus $(E)$, plasticity index $(H / E)$ and resistance index $\left(H^{3} / E^{2}\right)$. This was demonstrated by corresponding measurements of deformed samples. As an example, the imprints applied to the cross section of sample at different distances from the friction surface are shown in Figure 7.

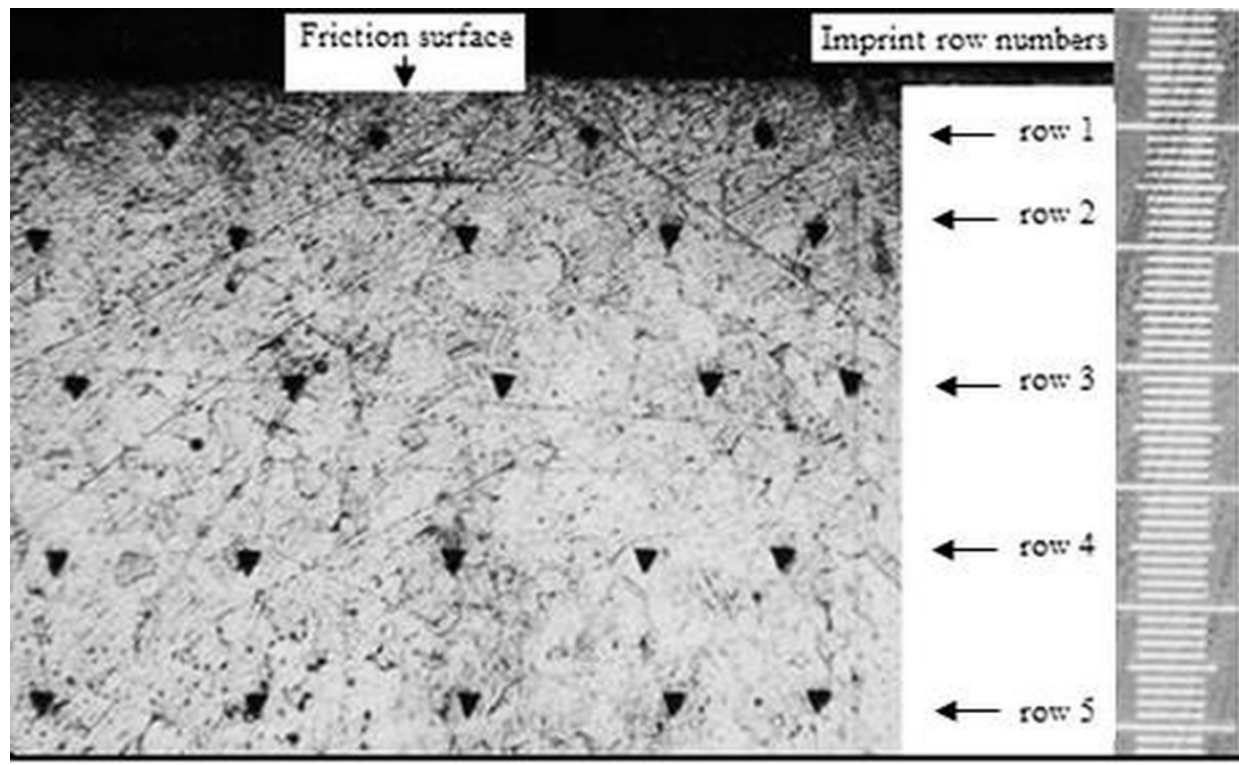

Figure 7. AISI 316L steel. Rows of imprints made on a cross section of sample after friction by the "metal/metal" method. A total of 7 rows have been completed. (A scale division corresponds to a distance of $10 \mu \mathrm{m}$ ).

The results of test and evaluations are shown in Figures $8-15$. Note that for all Figures the points closest to the ordinate axis correspond to a distance of about $50 \mu \mathrm{m}$ from the friction surface, with the latter on the right side at a distance of about $500-700 \mu \mathrm{m}$.

A characteristic feature of all the given parameters is a decrease in their values with an increase in the distance from the friction surface. Although in some cases the change is not entirely smooth, and regions with maxima and minima are noted, the following general picture is observed on all curves. 


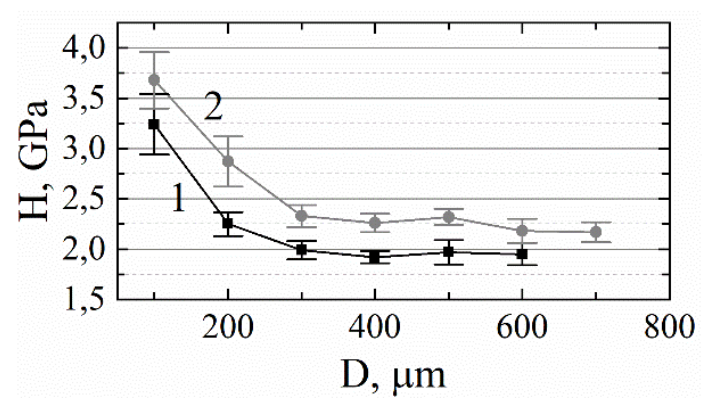

Figure 8. Dependence of hardness $(H)$ on the distance $(D)$ to the "metal/metal" friction surface. Curve 1 - friction for 1 hour; curve 2 - 10 hours.

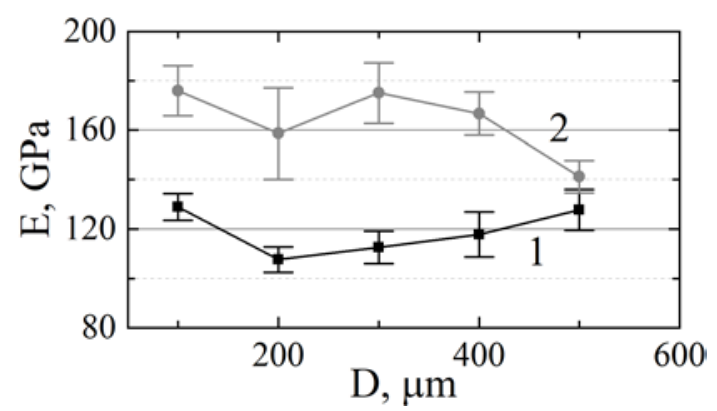

Figure 10. Change in Young's modulus $(E)$ with distance $(D)$ increasing to the "metal/metal" friction surface. Curve

1 - friction for 1 hour; curve 2 - 10 hours.

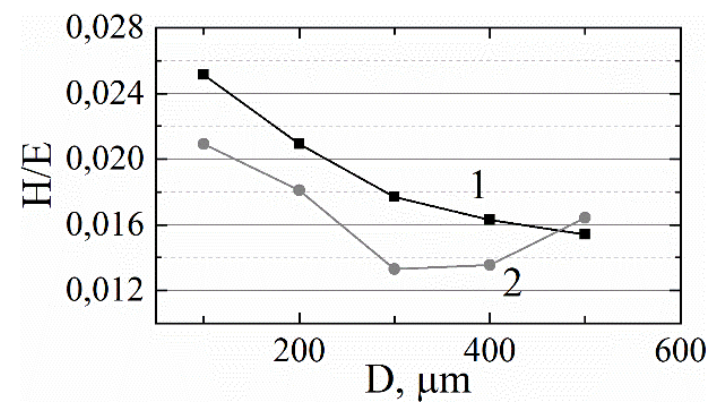

Figure 12. Modification of the plasticity index, $H / E$, as it moves away from the friction surface "metal/metal". Curve

1 - friction for 1 hour; curve 2 - 10 hours.

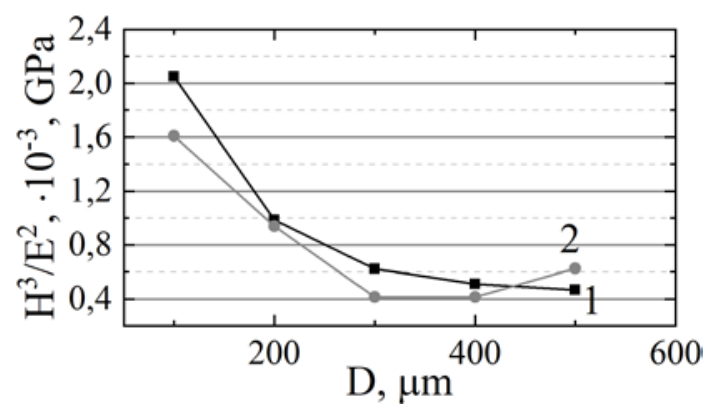

Figure 14. Modification of the resistance index, $H^{3} / E^{2}$, as it moves away from the friction surface "metal/metal". Curve 1 - friction for 1 hour; curve 2 - 10 hours.

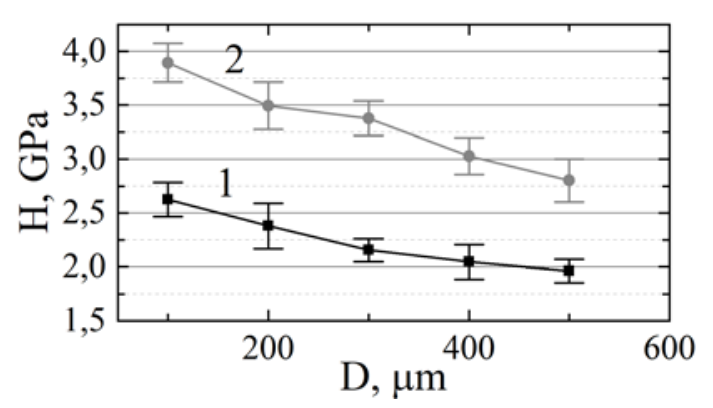

Figure 9. Dependence of hardness $(H)$ on the distance $(D)$ to the "metal/abrasive" friction surface. Curve 1 - friction for 1 hour; curve 2 - 5 hours.



Figure 11. Change in Young's modulus $(E)$ with distance $(D)$ increasing to the "metal/abrasive" friction surface. Curve 1 - friction for 1 hour; curve 2 - 5 hours.

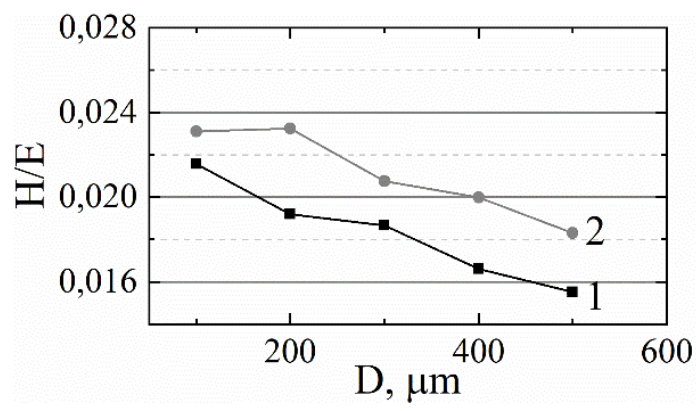

Figure13. Modification of the plasticity index, $H / E$, as it moves away from the friction surface "metal/abrasive". Curve 1 - friction for 1 hour; curve 2 - 5 hours.

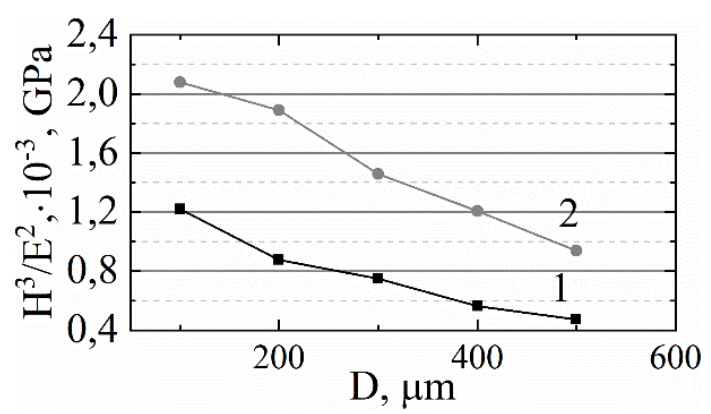

Figure 15. Modification of the resistance index, $H^{3} / E^{2}$, as it moves away from the friction surface "metal/abrasive". Curve 1 - friction for 1 hour; curve 2 - 5 hours. 
Firstly, the effect of friction leads to an increase in the value of parameters of strength and plasticity in comparison with the initial undeformed sample, and secondly, their value tends to decrease with distance from the friction surface to the values of the undeformed sample. The area covered by the effect of friction depends on the duration of the process, increasing with its increase. For the friction methods used in the work, the microstructure modification took place from the friction surface to about $700 \mu \mathrm{m}$ into the sample volume.

Finally, we mention that an increase in the duration of the friction process, as a rule, leads to the increase in all mechanical parameters (with some exceptions, for example, parameters $(H / E)$ and $\left(H^{3} / E^{2}\right)$ for the "metal/metal" friction method). Based on the results obtained, it can be stated that the friction method can be used to modify the parameters of strength and plasticity in the near-surface layers of metals.

\section{Conclusion}

The results of this paper demonstrates that different friction modes cause plastic changes in the deformed zone of the tested sample. The maximum modification of the structure takes place in a thin layer $(\approx 100 \mu \mathrm{m})$ immediately adjacent to the friction surface, i.e. in the zone of severe plastic deformation. The degree of deformation gradually decreases as it moves into the interior of the sample, and at a distance of about 600-700 $\mu \mathrm{m}$ from the friction surface, the sample acquires the form of the initial polycrystalline structure. Structural changes caused by friction are accompanied by similar changes in mechanical parameters such as microhardness $(H)$, Young's modulus $(E)$, plasticity index $(H / E)$ and resistance index $\left(H^{3} / E^{2}\right)$. The character and degree of their change can be regulated by the experimental conditions. Thereby, through the selection of appropriate modes, friction can be applied as a new method to obtain samples of austenitic stainless steel AISI 316L with the required mechanical properties.

Acknowledgement. This research work was fulfilled in the frame of the National Project no. ANCD 20.80009.5007.18.

\section{References}

1. Kragelskyi I. V. Trenie i iznos [Friction and wear]. Moscow: Mashinostroenie, 1968.

2. Panin V. E., Kolubaev A.V., Slosman A.I., Tarasov S. Yu., Panin S. V., Sharkeev. Iznos v parah trenia kak zadacha fizicheskoy mehaniki [Wear in friction pairs as a problem of physical mesomechanics].In: Physical mesomechanics. 2000, 3 (1), pp. 67-74.

3. Kolubaev A.V. Structural aspects of metal friction. In: Promising materials. Ed. Merson D. L., Tolyatti, 2013, 2 (5), pp. 1-62.

4. Reid J.V., Schey J.A. The effect of surface hardness on friction. In: Wear, 1987, 118 (1), pp. 113-125.

5. Pan L., Kwok C.T., Lo K.H. Friction-stir processing of AISI 440C high-carbon martensitic stainless steel for improving hardness and corrosion resistance. In: Journal of Materials Processing Technology, 2020, 277, 116448.

6. Hajian M., Abdollah-Zadeh A., Rezaei Nejad S.S., Assadi H., Hadavi S.M.M., Chung K., shokouhimehr M. Microstructure and mechanical properties of friction stir processed AISI 316L stainless steel. In: Materials and Design, 2015, 67, pp. 82-94.

7. Weigiang W., Shishu W. In situ observation and study of the unlubricated wear process. In: Wear, 1994, 171 (1-2), pp. 19-23.

8. Dogan H., Findik F., Morgul O. Friction and wear behaviour of implanted AISI 316L SS and comparison with a substrate. In: Materials and Design, 2002, 23, pp. 605-610. https://doi.org/10.1016/S02613069(02)00066-3. 
9. Charmi A., Falkenberg R., AVILA L., Mohr G., Sommer K., Ulbricht A., Sprengel M., Saliwan Neumann R., Skrotzki B., Evans A. Mechanical anisotropy of additively manufactured stainless steel 316L: An experimental and numerical study. In: Materials Science and Engineering: A, 2021, 799, 140154. https://doi.org/10.1016/j.msea.2020.140154.

10. Bajaj P., Hariharan A., Kini A., Kürnsteiner P., Raabe D., Jëagle E.A. Steels in additive manufacturing: A review of their microstructure and properties. In: Materials Science and Engineering: A, 2020, 772, 138633. https://doi.org/10.1016/j.msea.2019.138633.

11. Grabco D., Alexandrov S., Leu D., Rahvalov V., Shikimaka O. Behaviour of ductile materials under friction, extrusion and concentrated load action. In: Moldavian Journal of the Physical Sciences, 2004, 3(2), pp. 172177. http://sfm.asm.md/moldphys/

12. Grabco D. Z., Shikimaka O. A., Alexandrov S. E., Harea E. E., Mirgorodskaya I. YU., Danitsa Z. N. Evolution of change in microstructure of material as it moves farther from frictional contact surface under conditions of intense plastic deformation. In: Proceedings of the XVIII St. Petersburg: readings on the problems of crystal strength and growth, St. Petersburg, 2008, pp. 152-154.

13. Lyamina E., Alexandrov S., Grabco D. An approach to prediction of evolution of material properties in the vicinity of frictional interfaces in metal forming. In: Key Engineering Materials, 2007, 345-346, pp.741-744.

14. Alexandrov S.E., Grabco D.Z., Shikimaka O.A. The determination of the thickness of a layer of intensive deformations in the vicinity of the friction surface in metal forming processes. In: Journal Machinery Manufacture and Reliability, 2009, 38 (3), pp. 277-282.

15. Bespalov S.A. Металловедческие аспекты в процессах разрушения металлических материалов при трении [Metallic aspects in the processes of destruction of metallic materials during friction], In: Uspehi Fiziki Metallov, 2009, 10(4), pp. 415-435.

16. Tarasov S. Yu., Kolubaev A. V. Formation of surface layer with nanosize grain-subgrain structure due to friction of a copper - tool steel pair. In; Metal Science and Heat Treatment, 2010, 5 (3-4), pp. 183-188.

17. Grabco D., Shikimaka O., Pyrtsac C., Barbos Z., Popa M., Prisacaru A., Vilotic D., Vilotic M., Alexandrov S. Nano- and micromechanical parameters of AISI $316 \mathrm{~L}$ steel. In: Surface Engineering and Applied Electrochemistry, 2020, 56(6), pp. 719-726.

18. Grabco D., Shikimaka O., Pyrtsac C., Barbos Z., Popa M., Prisacaru A., Vilotic D., Vilotic M., Alexandrov S. Microstructures generated in AISI 316L stainless steel by Vickers and Berkovich indentations. In: Material Science and Engineering: A, 2021, 805, 140597. https://doi.org/10.1016/j.msea.2020.140597

19. Oliver W.C., Pharr G.M. An improved technique for determining hardness and elastic modulus using load and displacement sensing indentation experiments. In: Journal of Materials Research, 1992, 7(6), pp.15641580. https://doi.org/10.1557/JMR.1992.1564.

20. Rezaei-Nejad S. S., Abdollah-Zadeha A., Hajian M., Kargar F., Seraj R. Formation of nanostructure in AISI 316 austenitic stainless steel by friction stir processing. In: Procedia Materials Science, 2015, 11, pp. 397 402. http://creativecommons.org/licenses/by-nc-nd/4.0\%. 